\title{
A Case of Ovarian Endodermal Sinus Tumor Associated with Pregnancy
}

\author{
Kozo Ito, Kensaku Teshima, Hiroshi Suzuki and \\ KiICHIRo Noda \\ Department of Obstetrics and Gynecology, Kinki University \\ School of Medicine, Osaka 589
}

Ito, K., Teshima, K., Suzuni, H. and Noda, K. A Case of Ovarian Endodermal Sinus Tumor Associated with Pregnancy. Tohoku J. exp. Med., 1984, 142 (2), 183-194 — A case of a 25-year-old 2 gravida, 1 para pregnant woman in the 7 th week of gestation who was concurrented with endodermal sinus tumor (EST) is presented. Simple hysterectomy with left salpingo-oophorectomy, wedge resection of the right ovary and omentectomy were done following D \& C. Histological features were identical to those described for EST by Teilum. Cytological findings of imprinted smears were characterized by cuboidal or columnar cells with vacuoles, naked-looking cells of various sizes, and cells with an extremely large nucleus/cytoplasm $(\mathrm{N} / \mathrm{C})$ ratio. Measurements were made on serum alpha-fetoprotein and immunosuppressive acidic protein. The frequency of malignant ovarian tumors associated with pregnancy in the literature and at our clinic, and the treatment for it were discussed.—ovary; pregnancy; endodermal sinus tumor, histological feature; cytological findings

It has been reported that an ovarian endodermal sinus tumor (EST) originates from the germ cell of the ovary (Teilum 1959). EST is extremely malignant and tends to occur in young women, though the incidence is extremely low. As regards statistical analysis of the incidence, we have to rely on cases accumulated at many institutions for a long time. Kurman collected a total of 71 patients with EST for a period of 30 years (Kurman and Norris 1976a). Jimerson and Woodruff (1977a) reported 41 patients developing EST and later, 18 patinets with embryonal carcinoma (1977b). An ovarian malignant tumor associated with pregnancy remains still as a case report, and the exact incidence of the disease is little clarified. Jubb (1963a) studied 34 patients collected from the reports from eight institutions in Toronto City between 1882 and 1963, and found that a malignancy rate in the ovarian tumors associated with pregnancy was $2.2-5.0 \%$. Munnell (1963) also reported the rate of malignant ovarian tumor in pregnant women is one to 18,000 of delivaries for 15-year period and Chung and Birnbaum (1973), one to 25,000 of delivaries between 1951 and 1970 .

This paper presents an EST which developed in a patient in the seventh week of pregnancy. The EST was investigated histologically and cytologically.

Received for publication, May 12, 1983. 
Measurements were made on serum alpha-fetoprotein (AFP) as a tumor maker and serum immunosuppressive acidic protein (IAP) which was considered to be an indicator of therapeutic effects.

\section{Case Report}

A 25-year-old housewife, gravida 2, para 1.

Menstrual history. Menarche at the age of 12 years. Regular menstrual cycle of 28 days. Her last menstrual cycle began on 22nd July, 1981 and lasted for 6 days.

Chief complaints. Amenorrhea, a mass in the lower abdomen.

Present illness. The patient noticed a mass in her lower abdomen at the end of July, 1981. Afterward, the size of the mass increased. On 9th of September, nausea and vomiting appeared. On 10th of September, she visited our clinic. Pelvic examinations disclosed that a soft goose-egg-sized uterus was associated with a hard tumor of infant's head-size at its front. She was diagnosed as being in the seventh week of pregnancy, and the co-existence of solid ovarian tumor was also suggested. She was admitted to the hospital on 11th of September, 1981.

\section{Findings on admission}

She was $162 \mathrm{~cm}$ tall and weighed $53 \mathrm{~kg}$. Her blood pressure was 120/70 $\mathrm{mmHg}$ and her pulse rate was $84 / \mathrm{min}$. No abnormalities were seen on the general findings.

Laboratory tests. The blood was type A, Rh-positive. No abnormality was observed in hematological test results. One and two hour values of blood sedimentation rate were 56 and $102 \mathrm{~mm}$, respectively. HCG was measured as 16.000 IU/liter in the urine. As regards blood chemistry, LDH was $425 \mathrm{U} /$ liter, alphafetoprotein (AFP) was $13,464 \mathrm{ng} / \mathrm{ml}$ and immunosuppressive acidic protein (IAP) was $700 \mu \mathrm{g} / \mathrm{ml}$. There were no abnormalities in urinalysis, electrocardiogram, pulmonary or respiratory data. Ultrasonography revealed that the uterus was $5 \times$ $6 \times 7 \mathrm{~cm}$ in size and had a gestational sack (GS) in its center. At the front of the uterus, there was a shadow of mass measuring $14 \times 15 \times 17 \mathrm{~cm}$. The mass had multilocular profiles with some solid parts, and its wall looked slightly thick (Fig. 1). On 16th of September, 1981, D \& C was conducted because the patient as well as her family strongly desired to undertake it. Fig. 2 shows the histological feature of the material from her uterine cavity. CT scan was perfomed on 17th of September. The mass mostly occupied the pelvic cavity and slightly inclined to the left as shown in Fig. 3 . It measured $15 \times 15 \times 18 \mathrm{~cm}$ in size and consisted of three or four multilocular cysts. Its wall was sometimes thin and sometimes thick. In the solid part, a fine shade was diffused. On the basis of the these findings, the mass was diagnosed as the EST which occurred in the left ovary. Laparotomy was performed on 21st of September, 1981. 


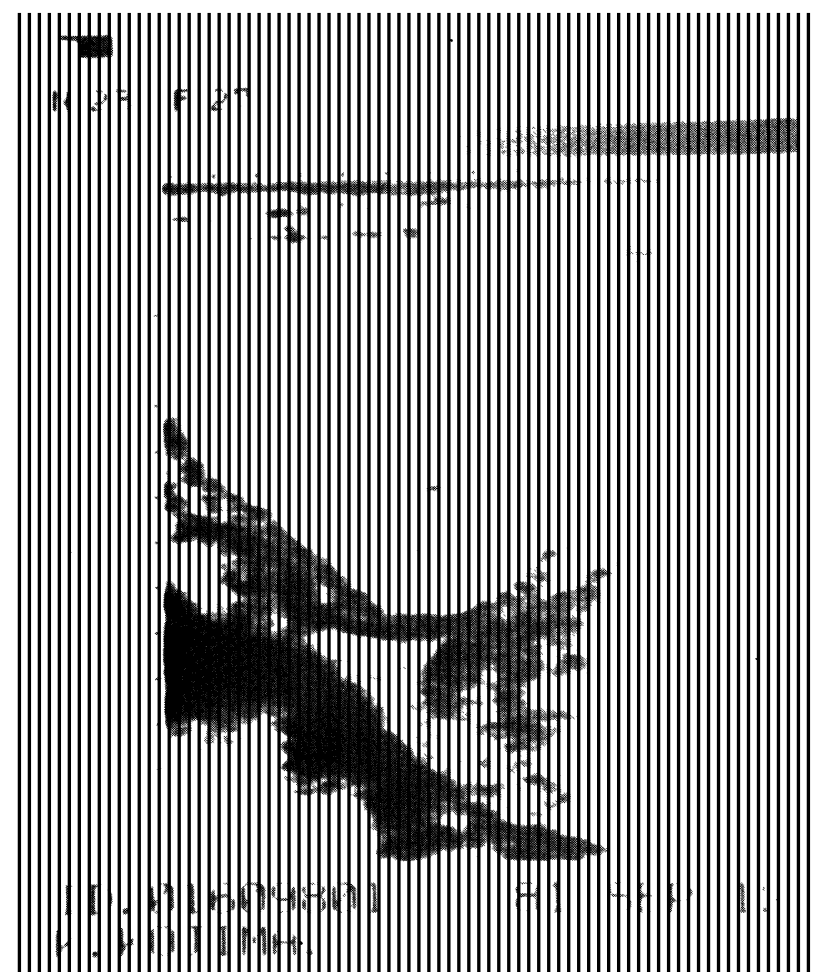

Fig. 1. Ultrasonography showing GS in the center of the uterus and a multilocular tumor of infant's head-size in front of the uterus.

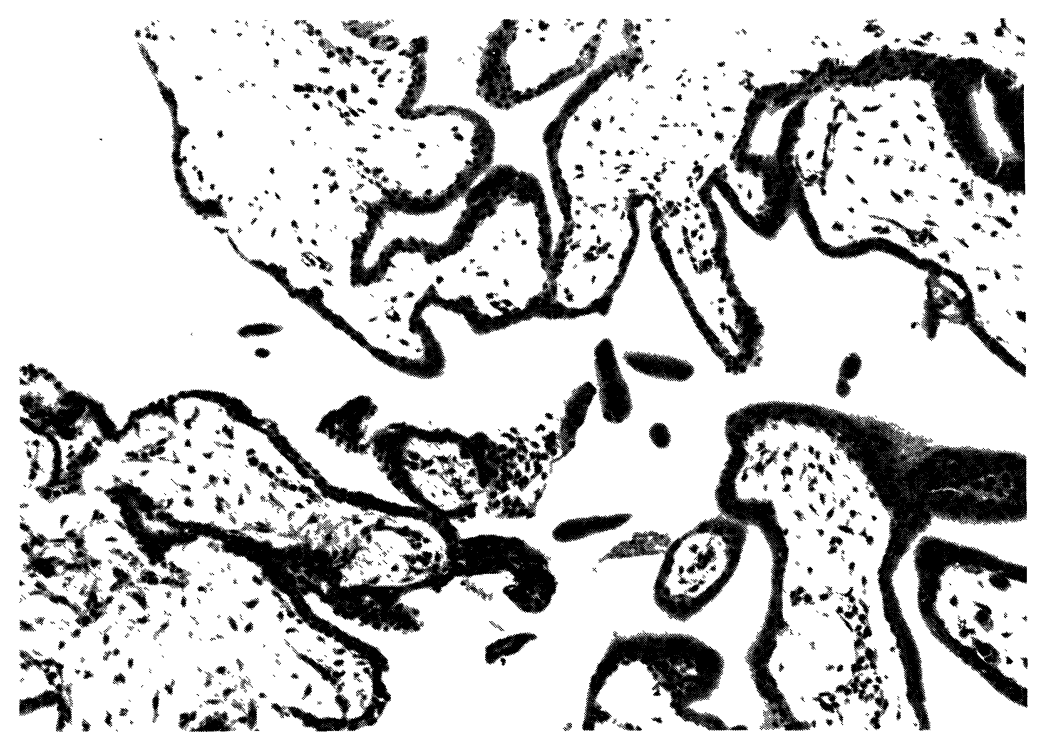

Fig. 2. Histological sample at D \& C in the seventh week of pregnancy presenting normal villous tissues. 


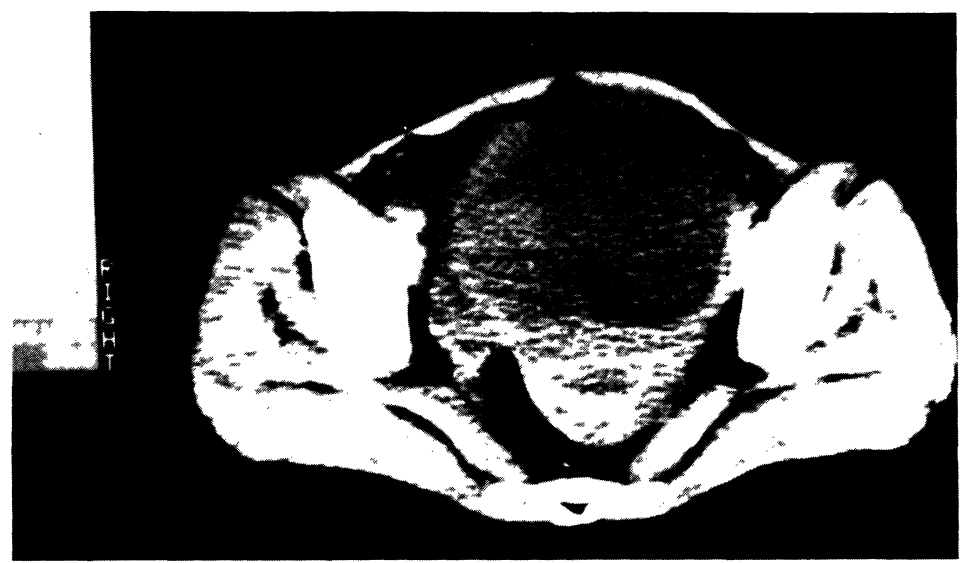

Fig. 3. CT scan disclosing the tumor with three or four multilocular cysts and diffused shade in the solid part.

\section{Findings on operation}

A median incision was made in the lower abdomen and about $10 \mathrm{ml}$ of ascites was observed. A new-born head-sized and a relatively soft tumor with smooth surface was found in the median portion, slighly extended to the left of the pelvic cavity beneath the abdominal wall. The tumor adhered to the frontal surface of the uterus and to the right adnexa. It was partly cystic but mostly solid. Water-like brown substances occupied the cysts. Simple hysterectomy with left salpingo-oophorectomy, wedge resection of the right ovary and omentectomy were done. A cross section of the cystic part was found to be multilocular and that of the solid part, slightly swollen and relatively soft, revealed a necrotized nest in its central region.

\section{Histological findings}

There existed follicular papillomatous structure where mainly cuboidal or columnar cells with little stroma divaricated irregularly (Fig. 4). Rough reticular structure, where relatively small spindle cells were arranged in the shape of a chain, was observed (Fig. 5). Also were seen eosinophilic hyaline globules which were diastase digestion resistant and PAS-staining positive (Fig. 6). According to Teilum and Kurman, these globules are characteristics of EST (Teilum 1959; Kurman and Norris 1976a). In addition, there were other cell groups consisting of cuboidal cells stained with light green and possessing oval nuclei with fine granular chromatin. Its $\mathrm{N} / \mathrm{C}$ ratio was extremely high. Lymphocytes infiltrated into the stroma (Fig. 7).

Cytological findings of imprinted cells

The imprinted cells from the cut surface of the tumor looked cuboidal or 


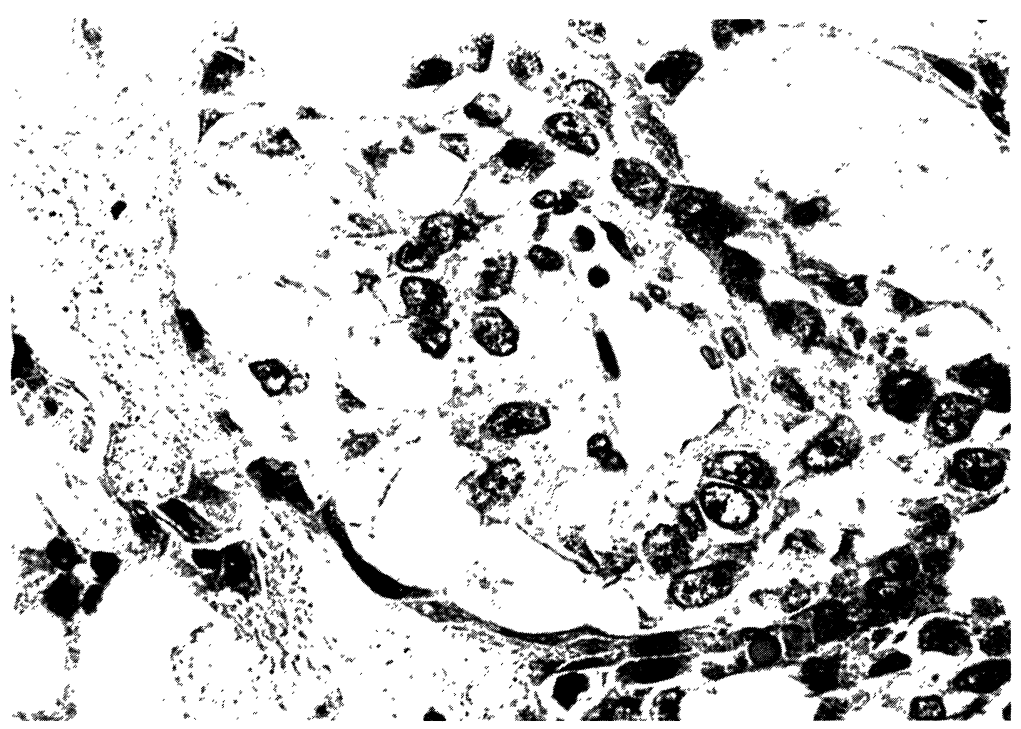

Fig. 4. Schiller Duval body characteristic of typical EST.

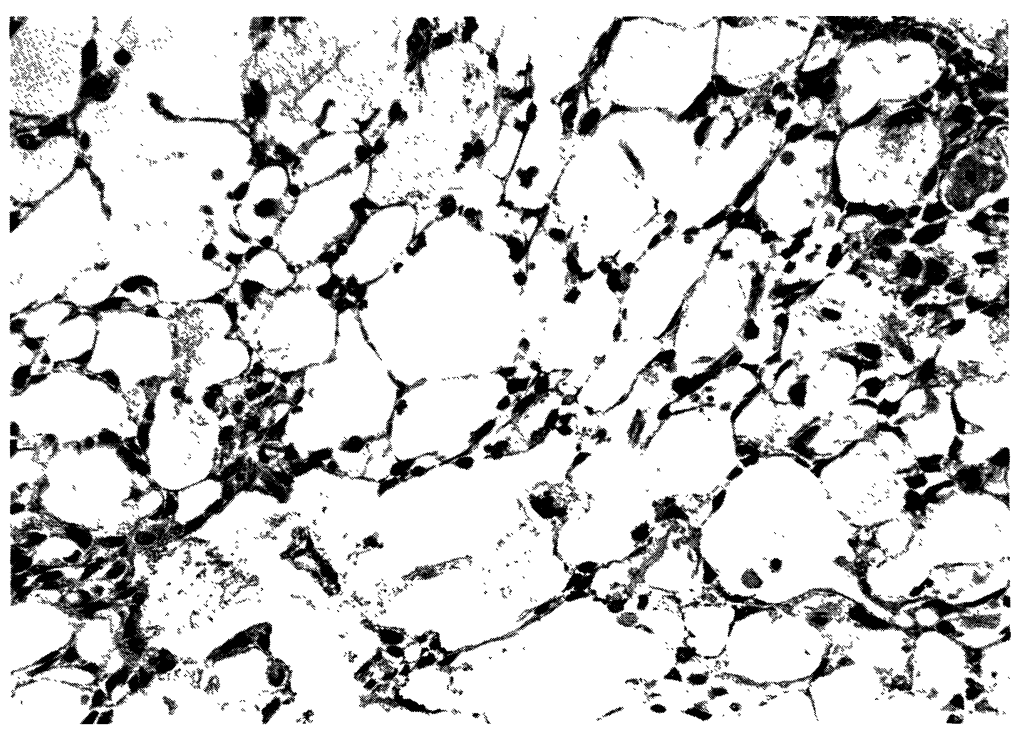

Fig. 5. Rough reticular structure consisting of cells with relatively light cytoplasm.

irregularly columnar, and had vacuole and thin cytoplasm stained with light green. They had mostly oval clear nuclei (Fig. 8) with a few large nucleolei. Naked-looking cells of various sizes were disseminated. Chromatin of these cells markedly increased in its quantity and showed a rough granular pattern. Distinct nucleolei were also observed. Other cells showed the following characteristics ; that is, they had scanty cytoplasms stained with light green, an extremely high $\mathrm{N} / \mathrm{C}$ ratio and moderately increased chromatin showing a rough 


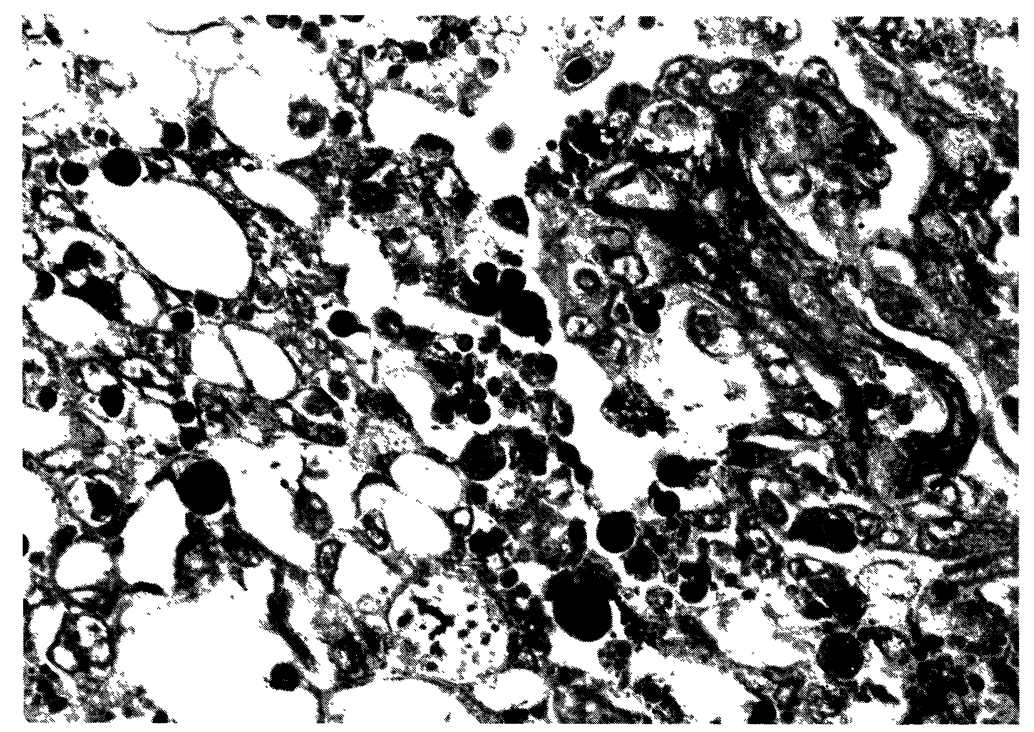

Fig. 6. Eosinophilic hyaline globules observed inside or outside EST cells.

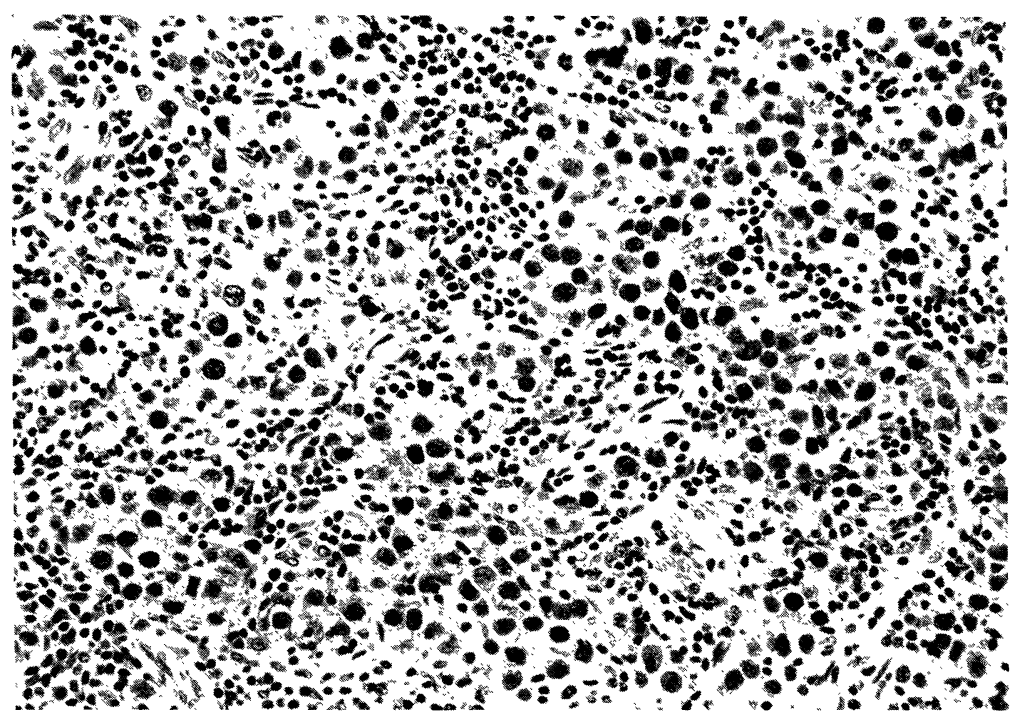

Fig. 7. The histological picture recognized as dysgerminoma from a part of this tumor.

granular pattern in their oval nuclei (Fig. 10).

\section{Postoperative course}

Ten mg mitomycin $\mathrm{C}$ was administered into the peritoneal cavity at the operation. Subsequently, $45 \mathrm{mg}$ of cisplatinum was given intravenously nine times weekly. High leveled AFP and IAP values before operation returned to 

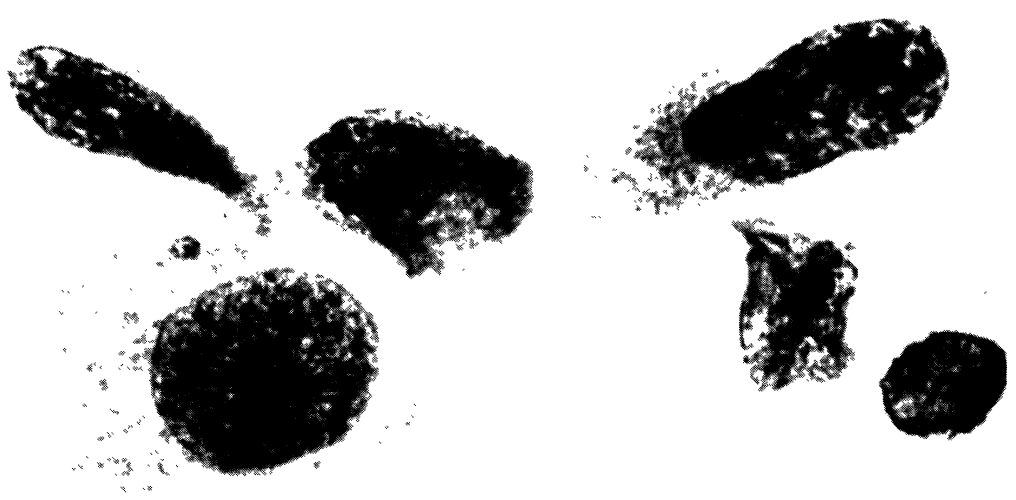

Fig. 8. Cytological findings of the imprinted cells where thin cytoplasm containing vacuoles was stained with light green. Nuclei were mainly oval showing a granular chromatin pattern.

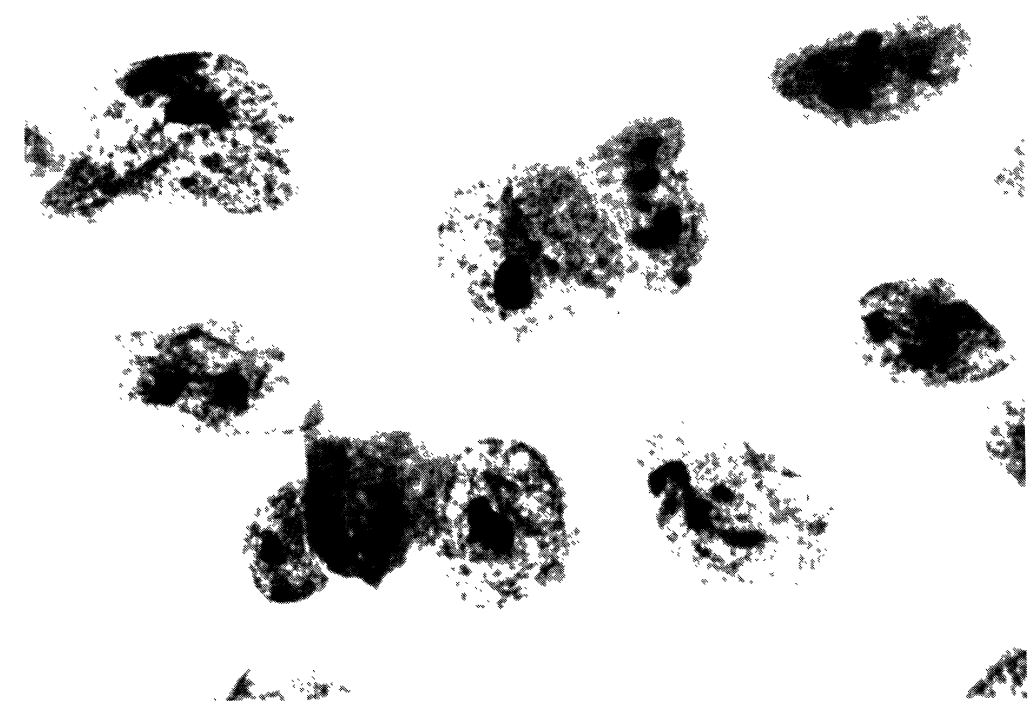

Fig. 9. The cell with two or three large red nucleoli.

normal 50 days and 30 days after operation, respectively (Fig. 11). On 28 th of November, 1981, the patient left the hospital. Afterward, she was orally given cyclophosphamide in a dose of $100 \mathrm{mg} /$ day. As of the present, no abnormalities are observed clincally or in various tumor markers. 


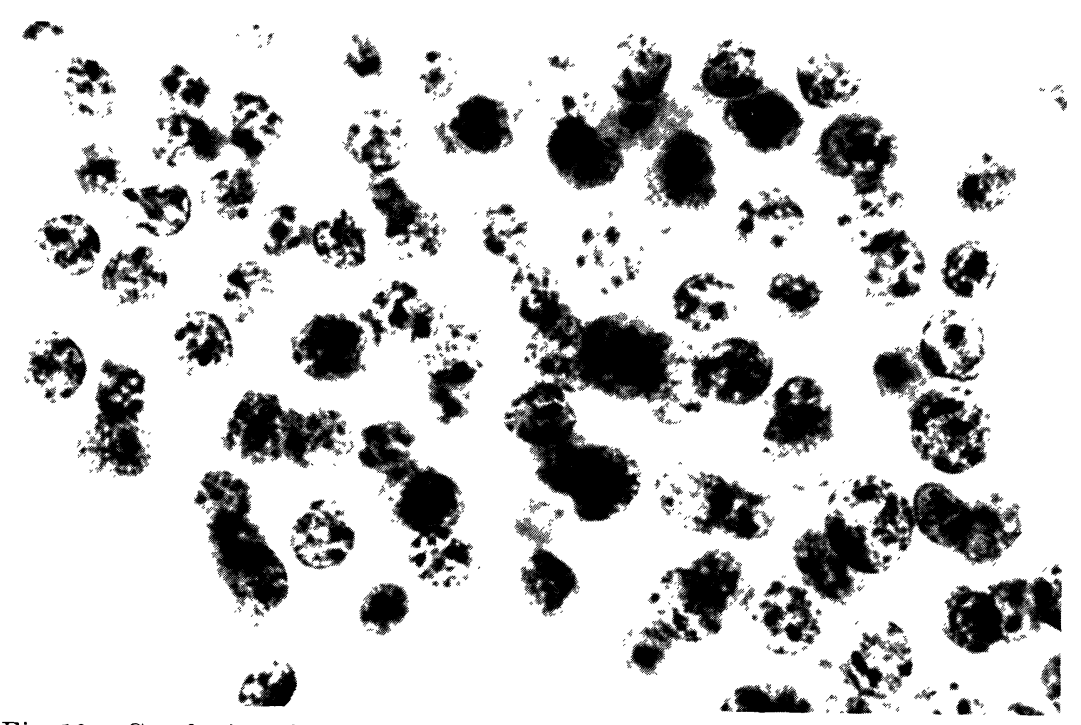

Fig. 10. Cytological findings of the imprinted cells obtained from dysgerminoma.

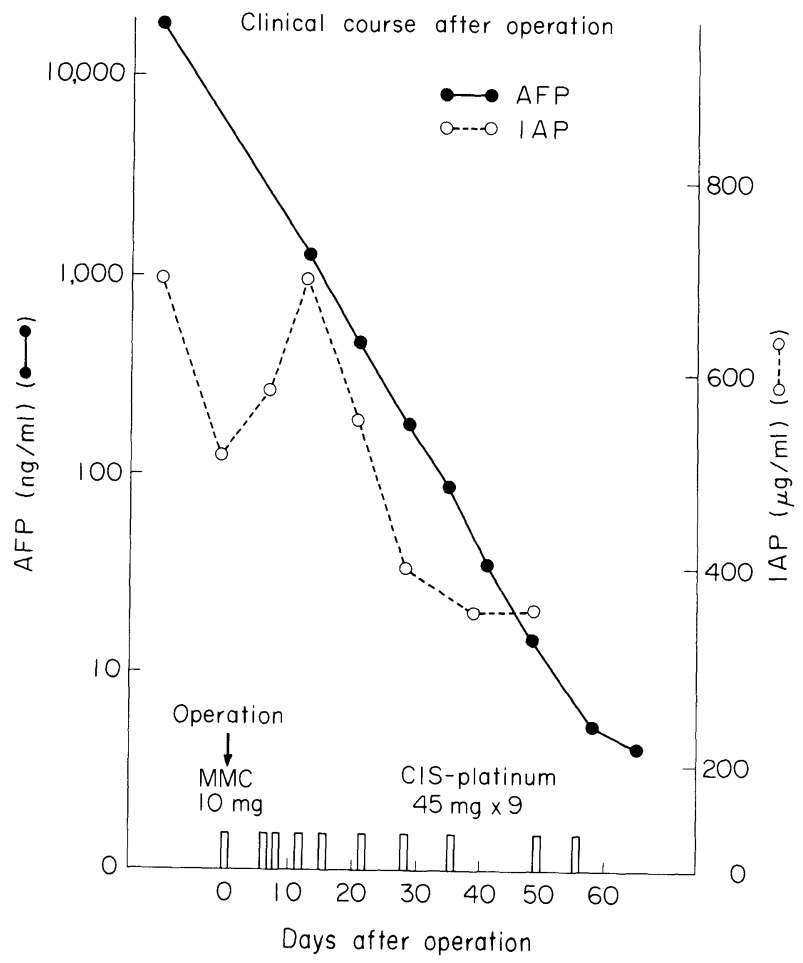

Fig. 11. Postoperative course. $10 \mathrm{mg}$ of $\mathrm{MMC}$ was given after operation and subsequent $45 \mathrm{mg}$ of cisplatinum was administered nine times. AFP and IAP values returned to normal 50 days and 30 days after operation, respectively. 


\section{Discussion}

Pregnancy induces dynamic changes in endocrinological activity throughout the female lives. Therefore such assumption may not be always misdirected that various ovarian tumors, especially malignant tumors derived from germ cells, are apt to appear during pregnancy. However, on our inquiry into the literature, only four cases of EST associated with pregnancy have been reported up to now. Jimerson and Woodruff (1977a, b), Weed et al. (1979), Petrucha et al. (1980) and Schwartz et al. (1983) described each one case of EST with pregnancy. Also Creasman et al. (1971) presented one case of embryonal carcinoma.

The reported incidence of ovarian tumors during pregnancy shows a great variety. One case of the ovarian tumor was observed out of 442 deliveries by Hill et al. (1975), 591 patients by Booth (1963), 800 patients by Chung and Birnbaum (1973), 814 patients by Tawa (1964), 938 patients by Beischer et al. (1971), 958 patients by White (1973) and 2,200 deliveries by Chowdhury (1962). In our clinic, one pregnant patient with ovarian tumor out of 170 deliveries was found. These differences in the incidence of ovarian tumors during pregnancy can be explained by varied techniques for diagnosis or indication of operation.

The rate of malignant tumors in the total number of ovarian tumors associated with pregnancy was calculated as $1.3 \%$ by Creasman et al. (1971), $2.4 \%$ by Buttery et al. (1973), 2.2-5\% by Jubb (1963b), 3\% by Chung and Birnbaum (1973), $4.2 \%$ by Chowdhury (1962), 4.4\% by Gustafson et al. (1954), 5.3\% by Hill et al. (1975), $5.7 \%$ by Tawa (1964), 7.9\% by Beischer et al. (1971) and $7.9 \%$ by White (1973). In our clinic, the rate of malignancy was $6.9 \%$. All of these are markedly lower than that of the patients without pregnancy, $10-15 \%$ in these papers or $17.8 \%$ in our clinic.

From these facts, it may be said that the rate of the malignant ovarian tumors associated with pregnancy is rather low. Beischer et al. (1971) have explained that such differences in the rate of malignant ovarian tumor are caused by the difference in age distribution between non-pregnant and pregnat women. Namely, $85.5 \%$ of the patients with malignant ovarian tumor were over 40 years old and those patients were rarely pregnant. In our clinic, $62.2 \%$ of the patients with malignant ovarian tumor belonged to the group of 40 years old or more.

EST is considered to be one of the most malignant ovarian tumors. Fortunately it is rather rare for a gynecologist to encounter patients who have developed EST during pregnancy, as described before. How pregnancy influences EST or how EST influences pregnancy has been discussed only by Petrucha et al. (1980). They described that pregnancy brought about no effects on the prognosis of EST. In our patient, neither clinical, histological nor cytological findigs indicated that EST and dysgerminoma were somewhat influenced by pregnancy.

Malignant ovarian tumors associated with pregnancy tend to progress asmyp- 
tomatically like benign ovarian tumors. They do not develop clinical symptoms in their early stages as most malignant diseases do not. Therefore, we are facing some difficulties in making a correct diagnosis of ovarian cancer in pregnancy. Jubb (1963b) accumulated a total of 34 patients with ovarian cancer, and Creasman et al. (1971),17 patients. They just obtained clinical symptoms similar to those observed in nonpregnant women with ovarian cancer. In some patients, there appeared abdominal swelling which was not commensurate with gestation weeks, pain and/or distress in the lower abdomen, and pressure on the urinary bladder and/or the rectum, when the ovarian tumors had grown up to some extent. But a huge gravid uterus makes pelvic examinations insufficient, and also it is impossible to conduct CT scan and pelvic angiography. So, the diagnosis is further difficult in pregnant patients than in nonpregnant ones. Sufficient bimanual pelvic examinations should be performed carefully to confirm whether ovarian tumor is present or not, whether tumor is cystic or solid, whether it infiltrates into the cul-de-sac and how abruptly it increases in size.

On these occasions, ultrasonography may be helpful for the diagnosis. Blood sedimentation rate and $\mathrm{LDH}$ value are hard to work as the indicator of malignant ovarian tumor when the patient is pregnant. Also AFP value has the similar tendency, but so high value of AFP more than $500 \mathrm{ng} / \mathrm{ml}$ can be useful for the diagnosis of EST, because its value in healthy pregnant woman is limited in the same level or lower according to Seppälä and Ruoslahti (1973).

Concerning the treatment of ovarian cancer, Disaia et al. (1974) proposed the following eight conditions to conduct conservative operation ; (1) cancer classified as stage Ia, (2) well differentiated mucinous, endometrioid or mesonephric histology (3) a young woman of low parity, (4) otherwise normal pelvis, (5) encapsulated and free of adhesions, (6) no invasion of capsule, lymphatics, or mesovarium, (7) peritoneal washings negative, (8) ovarian wedge biopsy and omental biopsy negative, and (9) close follow up. Munnell (1963), and Graver and Barber (1973) also indicated that when low grade mucinous cystadenocarcinoma, arrhenoblastoma, dysgerminoma, granulosa theca cell tumor or low grade papillary tumor is observed at its Stage Ia during pregnancy, the disease can be treated only by resection of an affected ovary.

Kurman and Norris (1976a, b) compared the postoperative result after resection of an affected adnexa with that after simple hysterectomy and bilateral salpingo-oophorectomy on a total of 24 patients developing Stage I EST. As a result, there were no differences between the two groups. Kurman and Norris (1976b) obtained similar results on 20 patients with mixed germ cell tumor of Stage I. Jimerson and Woodruff (1977a, b) supported these results. So, conservative operation can be considered when the patient with Ia Stage EST expects her baby eagerly. On the other hand, there are many lines of that the prognosis of EST is very poor. Jimerson and Woodruff (1977a) reported 31 out of 34 patients died within two years. According to Kurman and Norris (1976a), out of 
65 patients, only nine women survived $2.2-13.7$ years. Any way, operation must be the first choice in the treatment of EST. But, consecutive chemotherapy such as VAC therapy or cisplatinum therapy should be conducted on advanced cases.

\section{References}

1) Beischer, N.A., Buttery, B.W., Fortune, D.W. \& Macafee, A.J. (1971) Growth and malignancy of ovarian tumors in pregnancy. Aust. N.Z.J. Obstet. Gynaecol., 11, 208-220.

2) Booth, R.T. (1963) Ovarian tumors in pregnancy. Obstet. Gynecol., 21, 189-193.

3) Buttery, B.W., Beischer, N.A., Fortune, D.W. \& Macafeec, A.J. (1973) Ovarian tumors in pregnacny. Med. J. Aust., 1, 345-349.

4) Chowdhury, N.N.R. (1962) Ovarian tumors complicating pregnancy. Amer. J. Obstet. Gynecol., 83, 615-618.

5) Chung, A. \& Birnbaum, S.J. (1973) Ovarian cancer associated with pregnancy. Obstet. Gynecol., 41, 211-214.

6) Creasman, W.T., Rutledge, F.N. \& Smith, J.P. (1971) Carcinoma of the ovary associated with pregnancy. Obstet. Gynecol., 38, 111-116.

7) Disaia, P.J., Townsend, D.E. \& Morrow, C.P. (1974) The rationale for less than radical treatment for gynecologic malignancy in early reproductive years. Obstet. Gynecol. Surg., 29, 581-593.

8) Graver, E.A. \& Barber, H.R.K. (1973) Ovarian tumors in pregnancy. In: Surgical Disease in Pregnancy, edited by H.R.K. Barber \& E.A. Graber, W.B. Saunders Co., Philadelphia, pp. 428-439.

9) Gustafson, G.W., Gardiner, S.H. \& Stout, F. E. (1954) Ovarian tumors complicating pregnancy. Amer. J. Obstet. Gynecol., 67, 1210-1223.

10) Hill, L.M., Johnson, C.E. \& Lee, R.A. (1975) Ovarian surgery in pregnancy. Amer. J. Obstet. Gynecol., 122, 565-569.

11) Jimerson, G.K. \& Woodruff, J.D. (1977a) Ovarian extraembryonal teratoma. I. Endodermal sinus tumor. Amer. J. Obstet. Gynecol., 127, 73-79.

12) Jimerson, G.K. \& Woodruff, J.D. (1977b) Ovarian extraembryonal teratoms. II. Endodermal siuns tumor mixed with other germ cell tumors. Amer. J. Obstet. Gynecol., 127, 302-305.

13) Jubb, E.D. (1963a) Primary ovarian carcinoma in pregnancy. Amer. J. Obstet. Gynecol., 85, 345-354.

14) Jubb, E.D. (1963b) Primary ovarian carcinoma in pregnancy. Amer. J. Obstet. Gynecol., 85, 345-354.

15) Kurman, R.J. \& Norris, H.J. (1976a) Endodermal sinus tumor of the ovary: A clinical and pathological analysis of 71 cases. Cancer, 38, 2404-2419.

16) Kurman, R.J. \& Norris, H.J. (1976b) Malignant mixed germ cell tumors of the ovary. Obstet. Gynecol., 48, 579-589.

17) Munnell, E.W. (1963) Primary ovarian cancer associated with pregnancy. Clin. Obstet. Gynecol., 6, 983-993.

18) Petrucha, R.A., Ruffolo, E., Messina, A.M., Bouis, D. \& Praphar, H. (1980) Endodermal sinus tumor: Report of a case associated with pregnancy. Obstet. Gynecol., 55, 90s-93s.

19) Schwartz, R.P., Chatwani, A.J., Strimel, W. \& Putong, P.B. (1983) Endodermal sinus tumor in pregnancy: Roport of case and review of the literature. Gynecol. Oncol., 15, 434-439.

20) Seppälä, M. \& Ruoslahti, E. (1973) Alpha-fetoprotein in maternal serum : A new marker for detection of fetal distress and intrauterine death. Amer. J. Obstet. Gynecol., 115, 48-52. 
21) Tawa, K. (1964) Ovarian tumors in pregnancy. Amer. J. Obstet. Gynecol., 90, 511516.

22) Teilum, G. (1959) Endodermal sinus tumor of the ovary and testis. Comparative morphogenesis of so-called mesonephroma ovarii (Schiller) and extraembryonic (yolk sac-allantoic) structures of the rat's placenta. Cancer, 12, 1092-1105.

23) Weed, J.C., Roh, R.A. \& Mendenhall, H.W. (1979) Recurrent endodermal sinus tumor during pregnancy. Obstet. Gynecol., 54, 653-656.

24) White, K.G.(1973) Ovarian tumors in pregnancy. Amer. J. Obstet. Gynecol., 116, 544-550. 